
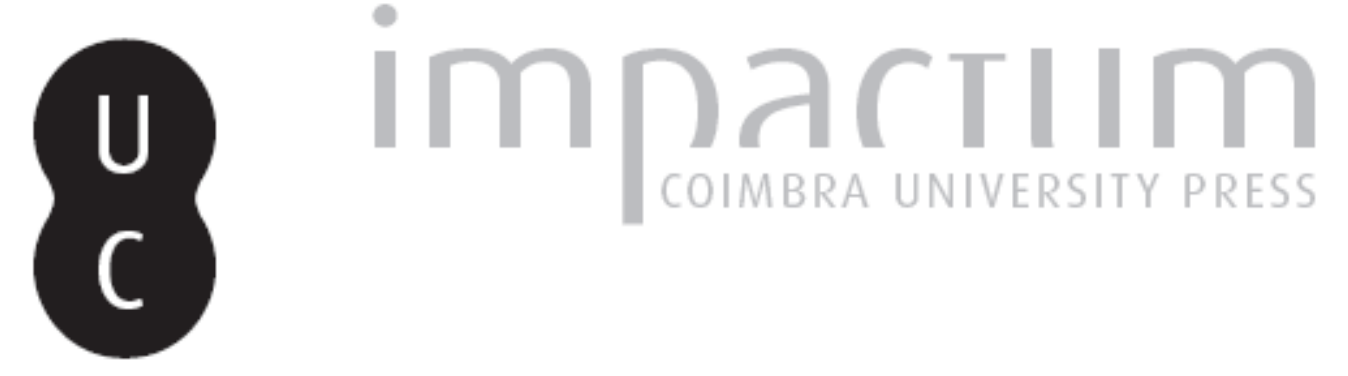

\title{
La convivencia entre militares y civiles en Petavonivm: una oportunidad para el evergetismo de los caballeros romanos
}

Autor(es): $\quad$ Jiménez de Furundarena, Agustín; Hernández Guerra, Liborio

Publicado por: Imprensa da Universidade de Coimbra

URL persistente:

URI:http://hdl.handle.net/10316.2/45388

DOI:

DOI:https://dx.doi.org/10.14195/1647-8657_38_3

Accessed : $\quad$ 26-Apr-2023 12:34:46

A navegação consulta e descarregamento dos títulos inseridos nas Bibliotecas Digitais UC Digitalis, UC Pombalina e UC Impactum, pressupõem a aceitação plena e sem reservas dos Termos e Condições de Uso destas Bibliotecas Digitais, disponíveis em https://digitalis.uc.pt/pt-pt/termos.

Conforme exposto nos referidos Termos e Condições de Uso, o descarregamento de títulos de acesso restrito requer uma licença válida de autorização devendo o utilizador aceder ao(s) documento(s) a partir de um endereço de IP da instituição detentora da supramencionada licença.

Ao utilizador é apenas permitido o descarregamento para uso pessoal, pelo que o emprego do(s) título(s) descarregado(s) para outro fim, designadamente comercial, carece de autorização do respetivo autor ou editor da obra.

Na medida em que todas as obras da UC Digitalis se encontram protegidas pelo Código do Direito de Autor e Direitos Conexos e demais legislação aplicável, toda a cópia, parcial ou total, deste documento, nos casos em que é legalmente admitida, deverá conter ou fazer-se acompanhar por este aviso.

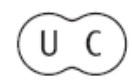


UNIVERSIDADE DE COIMBRA

FACULDADE DE LETRAS

\section{CONIMBRIGA}

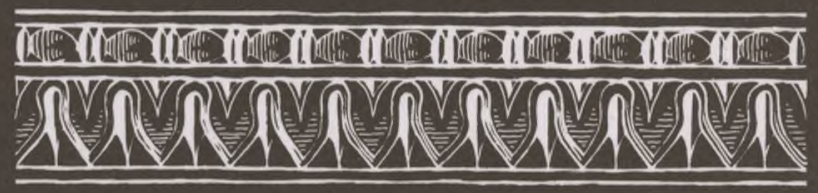

VOLUME XXXVIII - 1999 
Agustín JiMÉNEZ DE FURUNDARENA

Doctor en Historia Antigua

LIBORIO HERNÁNDEZ GUERRA

Profesor Titular de Historia Antigua, Universidad de Valladolid

LA CONVIVENCIA ENTRE MILITARES Y CIVILES EN PETAVONIVM:

UNA OPORTUNIDAD PARA EL EVERGETISMO

DE LOS CABALLEROS ROMANOS

"Conimbriga" XXXVIII (1999) p. 65-74

RESUMEN: La existencia de dos aras votivas procedentes del campamento del Ala II Flavia Hispanorum Civium Romanorum en Petavonium (Rosinos de Vidríales, Zamora, España) permite analizar las relaciones entre los mandos de una unidad del ejército imperial y una comunidad civil, aspecto poco conocido normalmente a través de las fuentes epigráficas y literarias.

RÉSUMÉ: L'existence au campement de Y Ala II Flavia Hispanorum Civium

Romanorum à Petavonium (Rosinos de Vidríales, Zamora, España) de deux inscriptions votives rend possible l'étude des relations des commandants d'une unité de l'armée impériale avec une comunité civile, aspect normalement peu connu des souces épigraphiques et classiques. 
(Página deixada propositadamente em branco) 


\section{LA CONVIVENCIA ENTRE MILITARES Y CIVILES EN PETAVONIVM: UNA OPORTUNIDAD PARA EL EVERGETISMO DE LOS CABALLEROS ROMANOS}

El ejército romano instalaba sus campamentos y bases de operaciones allí donde las necesidades tácticas y estratégicas hacían necesaria la presencia de una guarnición imperial. Los lugares escogidos solían estar alejados de los núcleos de población principales, lo que dificultaba las posibilidades de los soldados para satisfacer muchas de sus necesidades de objetos, ocio y cariño.

La solución a esta situación se producía de una forma relativamente rápida, ya que un campamento militar se convertía en un foco de atracción económica, que primero atraía a buhoneros y prostitutas, y que terminaba por generar un auténtico poblado civil anejo al militar, que recibía el nombre de cannaba (l).

Con el tiempo, este núcleo mercantil se transformaba progresivamente en un lugar civilizado, ya que los soldados, apagada la fogosidad de los años jóvenes, tendían a crear familias estables de hecho, convertidas en honorables familias de derecho con su licencia $\left(^{*}{ }^{2}\right)$.

Cuando este proceso avanzaba lo suficiente, el poblado civil se transformaba en una auténtica ciudad, con sus propios magistrados y un amplio margen de maniobra en sus asuntos internos. Si conseguía sobrepasar un cierto umbral de urbanización, como solía ocurrir en la

(0 J. M. RoldÁn HeRvás. "El Ejército Romano en Hispania", en La Guerra en la Antigüedad. Una Aproximación al Origen de los Ejércitos en Hispania. Madrid 1997, pp. 327-329.

(2) Suetonio. Aug. 49. G. WeBster. The Roman Imperial Army. Londres 1969, p. 94. M. ABSIL y Y. LE BOHEC. "La Liberation des Soldats Romains sous l'Haut Empire". Latomus XLIV, 4, 1985, p. 859 y notas. B. CAMPBELL. The Roman Army. 31 b.C.-a.D. 337. A Source Book. Londres-Nueva York 1994, p. 193. 
vecindad de las grandes fortalezas legionarias, la cannaba podía adquirir el codiciado y productivo status de municipium, accediendo, por concesión imperial, al pleno autogobierno, lo que la libraba de la injerencia de las autoridades militares.

En el campamento del Ala II Flavia Hispanorum Civium Romanorum en Petavonium, el proceso de creación de una ciudad civil, de una cannaba aneja al castellum alae, se aproxima bastante al modelo descrito. La diferencia se encuentra en que cuando el ala se instaló en su nueva base a finales del siglo I d.C., el núcleo civil de Petavonium ya existía. Esto se debía a que desde las guerras astur-cántabras hasta el año 63, la Legio X Gemina había tenido su base en esta localidad (3), y anejo al castra legionis se había desarrollado una cannaba $\left({ }^{4}\right)$.

Una prueba de la existencia de esta cannaba de origen legionario es la inscripción del veteranus de la Legio X Gemina M. Valerius Secundus hallada en Rosinos de Vidríales (5), que fue licenciado al final del imperio de Claudio o bajo el de Nerón:

$\mathrm{M}$ (arcus) VALERIVS P (ublii) / F (ilius) ANI (ensi tribu) SECVNDVS / VETER (anus) H (ic) S (itus) E (st)

Esta cannaba sobrevivió a la marcha de la legión, ya que se encontraba situado en un lugar privilegiado, sobre la vía que desde Asturica Augusta llevaba a Bracara Augusta, camino de comercio y riqueza para su población, como atestiguan los itinerarios al con-

(3) R. Martín Valls Y G. Delibes de Castro. "Sobre los Campamentos de Petavonium" Studia Archaeologica 36 1975, p. 6. J. Alvarez SANZ DE Buruaga. "La Fundación de Mérida”. Augusta Emerita. Actas del Bimilenario de Mérida. Madrid, 1976, p. 21. J.M. SolanA. "Caucenses, Amallobrigenses e Intercatienses y sus Primeros Contactos con Roma", in Actas del I Congreso de Historia de Zamora, Zamora 1989. p. 314. A. Liberati y F. Silverio. Vita e Costumi dei Romani Antichi: V Organizzazione Militare: Esercito, Roma 1988, 84. Sobre el traslado de la unidad a Pannonia, A. Mocsy. "Pannonia". RE. IX suppl. col. 613. A. R. NEUMAnN. Vindobona. Viena 1980, pp. 14-15. K. GENSER. Der Österreichische Donaulimes in der Römer Zeit. Viena 1986, pp. 631-632 y 634.

$\left({ }^{4}\right)$ S. Carretero Vaquero y Ma.V. Romero Carnicero. los Campamentos Romanos de Petavonium (Rosinos de Vidríales, Zamora). Valladolid 1.997, p. 45.

$\left(^{5}\right) C i L$ II, $263=I L E R 5225=$ P. LE ROUX. REA. LXXVII, 1975, p: 147, n. $3=$ P. LE Roux. L'Armée Romaine et les Provinces Ibériques d'Auguste à Dioclétien. Paris 1982 , p. 182, n. $^{\circ} 40$. 
siderar Petavonium como una mansio de dicha vía, la XVII (6), y también Ptolomeo, que indica que este núcleo era una de las poleis de los Astures Superados $\left({ }^{7}\right)$.

Sin embargo, no todo fueron luces, ya que la marcha de la legión debió suponer un duro golpe para los habitantes de la localidad, cuya forma de vida se apoyaba en la presencia de la unidad y de toda el movimiento de riqueza que sus 5.500 hombres generaban, por lo que la segunda mitad del siglo I d.C. debió significar un período de readaptación a una nueva situación $\left({ }^{8}\right)$, llevando, casi seguro, una vida vegetativa.

La decisión imperial de instalar el Ala II Flavia Hispanorum Civium Romanorum en los terrenos del antiguo castra de la Legio $X$ Gemina $\left({ }^{9}\right)$ fue una oportunidad para el desarrollo del núcleo de Petavonium, que consiguió crecer con este nuevo impulso, hasta alcanzar la nada desdeñable superficie de 90 ha. $\left({ }^{10}\right)$, dentro del umbral urbano.

Las relaciones entre la comunidad hispanorromana de Petavonium y el ala y sus mandos debieron ser bastante fluidas, y a buen seguro ambas autoridades, civiles y militares, intentaron convivir de la mejor forma posible, respetando mutuamente sus prerrogativas y zonas de influencia.

Tanto a los praefecti alae como a las autoridades locales, a los que no resulta demasiado arriesgado llamar, al menos, premagistrados, les interesaba mantener buenas relaciones, ya que ambos obtenían beneficios de la coexistencia.

Para el prefecto, tener un núcleo importante cerca significaba que podía confiar en que sus hombres serían bien atendidos, muchas veces por sus ex-camaradas que, tras su licencia, se habían instalado allí. También podía esperar que la posibilidad de formar familias estabi-

(6) It. Ant. 423, 3.

(7) Ptolomeo. II, 6, 34.

$\left({ }^{8}\right)$ S. Carretero Vaquero y Ma.V. Romero Carnicero. los Campamentos... p. 46.

(9) Gómez Moreno. CM Zamora, pp. 48-49. M. Vigil. "El Ala...” p. 110. A. García y Bellido. "El Ejército Hispano...”, p. 136. J.M. Roldán Hervás. Hispania... pp. 213-214. P. LE Roux. L'Armée... p. 214. P. LE RouX. "L’Armée Romaine dans la Péninsule Ibérique sous 1'Empire: Bilan pour une Decerne”. REA 94, 1992, 1-2, p. 233. R. Martín Valls, Ma.V. Romero Carnicero y S. Carretero Vaquero. "Aras Votivas..."p. 331 .

( $\left.{ }^{10}\right)$ S. Carretero Vaquero y Ma $\mathrm{M}^{\mathrm{a}}$ V. Romero Carnicero. los Campamentos..., p. 46. 
lizaría emocionalmente a sus hombres, que gastarían su paga en mantener a su mujer y sus hijos y no en francachelas que terminasen en desórdenes. Y por último, el Prefecto podía satisfacer muchas de sus necesidades personales a través de los comerciantes locales, e, incluso, mantener una agradable relación social, distinta de la jerárquica que tenía que sostener con sus oficiales y sus soldados.

La comunidad civil de Petavonium obtenía unos pingües beneficios de la presencia de los 512 jinetes del ala, que gastarían buena parte de la paga en el interior de la comunidad, bien con la formación de familias, bien con el uso de otros servicios. Además, siempre era posible aprovecharse de aquello que los comerciantes transportaban a la base del Ala por cuenta de la annona militaris, y acceder a algunos productos raros como el aceite o el vino de una cierta calidad.

Por lo tanto, en Petavonium mantener buenas relaciones entre el campamento militar y el núcleo civil era un objetivo prioritario para cualquiera de los prefectos que se sucedieron en el mando del ala a los largo del tiempo.

Esto permite poner en juego otro factor, ya que el jefe del ala, designado por el Emperador praefectus equitum alae, era siempre, como era normal, un miembro del ordo equester, es decir un personaje que pertenecía al segundo orden de la sociedad romana, poseedor de una fortuna propia, educado y civilizado, y que, por las características del cursus honorum ecuestre, llegaba a Petavonium para ejercer por 3 ó 4 años su tercera milicia, lo que le permitiría retirarse honorablemente a su lugar de origen, o bien, con el favor imperiai, acceder a las siempre lucrativas y prestigiosas procúratelas ecuestres, $\mathrm{y}$, tal vez, alcanzar la cúspide del estado romano como Prefecto del Pretorio, segundo hombre del Imperio $\left({ }^{n}\right)$.

Como miembros de un orden que consideraba el evergetismo como una costumbre social, los prefectos del ala podían sentirse inclinados a favorecer con él a la comunidad civil de Petavonium ( ${ }^{12}$ ),

(n) P. A. Holder. The Auxilia from Augustus to Trajan. BAR 70, Londres 1980, pp. 76 y 82.

(12) E. Melchor Gil. El Mecenazgo Cívico en la Bética. Córdoba 1994, pp. $33-$ -36, IDEM. "Consideraciones acerca del Origen, Motivación y Evolución de las Conductas Evergéticas en Hispania Romana”. Studia Historica XII, 1994, pp. 65-69, indica que una de las motivaciones de los evergetas municipales de Hispania era el deseo de obtener gloria y honores dentro de su comunidad, perpetuando su nombre y el de su familia. Evidentemente los evergetas militares compartían esa aspiración a la gloria. 
con la que lograrían estrechar más aún los lazos que unían al ala con su cannaba $\left({ }^{13}\right)$.

Conocemos el caso de dos prefectos del ala, que, a mediados del siglo II, pusieron en práctica este evergetismo en favor de la comunidad de Petavonium.

El africano M. Sellius Honoratus, natural del Municipium Aelium Choba (Ziamsa, Argelia, Mauretania Caesariense) edificó y consagró, cumpliendo un voto, varios templos en honor de Hércules (14), a finales del siglo II ( $\left.{ }^{15}\right)$, como indica esta inscripción $\left({ }^{16}\right)$ (cf. foto 1$)$ :

HERCVLI SACR[V]M / M \{arcus) SELLIVS L \{udi) F (ilius) ARN(ensi tribu) / HONORATVS DO/MO CHOBA EX PR/OVINCIA MAVR[E]/TANIA CAES(ariense) PRA[E]/F(£c/to) EQ(uitum) A(lae) II F(laviae) H(ispanorum) C(ivium) R(omanorum) / VOTORVM COMPO/S TEMPLA ALCIDI / DEO A FVNDAME/NTIS EXTRVXIT

Evidentemente, los templos no fueron edificados dentro del campamento del ala, ya que la tradición y la legislación militar concen-

(13) Tal vez pueda considerarse un paralelo la inscripción CIL II, 5690 procedente de León, en la que la posible esposa de un Legado de la Legio VII Gemina construyó un puente sobre un río - ¿el Torio o el Bernesga? - en favor de la comunidad civil de la cannaba de Legio VII Gemina. Cfr. J. MANGAS. "Puente Romano de la Legio VII Gemina (CIL II, 5690)". Studia Historica IV-V, 1986-87, pp. 245-251. También E. MELCHOR GiL. "La Construcción Pública en Hispania Romana: Iniciativa Imperial, Municipal y Privada". MHA XIII-XIV, 1992-93, p. 141. También en Legio, el Legado Q. Tullius Maximus erigió entre el 162 y el 166 un Templo en honor de Diana, que conocemos a través de la florida inscripción CIL II, 2660, sobre un ara, aunque en este caso es más que posible que nos encontremos ante algún tipo de capilla privada, que afectaba poco o nada a la vida de los habitantes de la cannaba de Legio.

(14) S. CARretero VAQuero y Ma. V. Romero CARnicero. Los campamentos... p. 46.

(15) M. VIGIL. "El Ala II Flavia". AEA XXXIV, 1961, p. 106, adelanta la fecha hasta el tránsito entre la primera y la segunda centuria. R. MARTín VALLS, Ma.V. Romero CARnicero y S. CARretero VAQuero. "Aras votivas del campamento de Petavonium". p. 343, piensan en la segunda mitad del siglo II.

(16) M. VigIL. "El Ala II Flavia". AEA XXXIV, 1961, P- 104, n. ${ }^{\circ} 1=$ A. GARCíA Y BELLIDO. AEA XXXIV, 1961, p. $105=A E$ 1963, $16=$ ILER $2069=$ CIM $436=\mathrm{T}$. MAÑANES. EN Ast. 109 = L. S AGREdo SAN EUSTAQUiO y A. JiMÉNEZ DE FuRUNDARENA. "La Religion Practicada por los Militares del Ejército Romano de Hispania durante el Alto Imperio. (Ss. I-III)”. ETE 9, 1996, p. 316, n. ${ }^{\circ} 2$. 
traban los cultos militares en el aedes del principia del campamento, y excluían de él las devociones no oficiales $\left({ }^{17}\right)$.

Por tanto, los templos debieron ser erigidos en el núcleo civil, para satisfacer las necesidades religiosas de algunos devotos de Hércules, además de las del propio prefecto, devotos que debían ser tanto militares como civiles.

Esta obra, según indica la inscripción, fue estrictamente privada del prefecto, ya que no aparece ninguna dedicación imperial, por lo que la dedicatoria y consagración del templo fue una muestra de la munificencia del Sellius Honoratus ${ }^{(18)}$.

La situación de estos templos de Hércules es muy difícil de precisar, sin embargo este ara votiva apareció en la Ermita de Santa María del Campo en Rosinos de Vidríales, por lo que no es muy descabellado pensar en una continuación del uso religioso en un espacio consagrado desde antiguo $\left({ }^{19}\right)$.

La otra muestra de evergetismo se la debemos a L. Versenus Aper, natural del Municipium Hispellum en la Regio VI de Italia, que a principios del imperio de Marco Aurelio fue prefecto del ala $\left({ }^{20}\right)$, y erigió un ara votiva para agradecer a la Fortuna la correcta finalización de la edificación de unos baños, como indica la siguiente inscripción (21) (Foto 2):

L(wdws) - VERSEN VS / APER-PRAEF(ecto) / ALAE OPERE / BAL $\{$ I $\}$ NEI-SVB SE / INCOHATO ET / CONS VMM A/TO FORTVNAE / L(ibens) \(otum) S(olvit)

(17) Cfr. J. Helgeland. "Roman Religion Army". ANRWII, 26.2, 1978, pp. 1470-1505. L. Sagredo san Eustaquio y A. JimÉnez de Furundarena. "La Religion Practicada por los Militares del Ejército Romano de Hispania durante el Alto Imperio Romano (ss. I-III)". ETF 9, 1996, pp. 289-301.

$\left({ }^{8}\right)$ E. Melchor GiL. "La Construcción..." pp. 144 y 151, Tabla 1, meniona esta munificencia, pero sin explicar porqué Sellius Honoratus la hizo. Además fecha la inscripción con una cronología muy baja, 69-117, cuando la inscripción es de mediados del siglo II.

(.9) S. Carretero Vaquero y Ma. V. Romero CARnicero. los campamentos... p. 46.

(20) R. Martín Valls, Ma. V. Romero Carnicero y S. Carretero Vaquero. “Aras Votivas..." p. 343.

(21) $A E$ 1937, 166 = R. MARTín VALLs. "Epígrafes Romanos de Sansueña (Rosinos y Santibañes de Vidríales)". Studia Archaeologica 75, Valladolid 1.975, p. $13=$ L. Sagredo san Eustaquio y A. JimÉnez de Furundarena. “La Religión...” p. 314, n. ${ }^{\circ} 1$. 
En los campamentos militares, lo soldados disponían siempre de un instalación termal con la que cubrir una necesidad higiénica y social, cual era el baño y el aseo personal. En los campamentos legionarios, las termas solían encontrarse en el interior del pomerium del campamento. Sin embargo, en los mucho más pequeños castella de los auxilia, los baños solían colocarse en las proximidades del campamento, pero fuera de él. Normalmente estas instalaciones eran una de las que contribuían a crear la cannaba, como ocurre en este caso $\left({ }^{22}\right)$.

Estas termas, aún sin localizar, debían ser utilizadas indistintamente por militares y civiles,tal vez utilizando los primeros los tiempos en los que los segundos realizaban labores propias de su oficio. Esto significa que las termas eran un lugar adecuado para el establecimiento de cordiales relaciones entre civiles y militares y entre los promagistrados de Petavonium y el prefecto del ala.

Por ello, no es extraño que Versenus Aper beneficiara con su munificencia a sus propios hombres y a la población civil de Petavonium con la construcción de unas nuevas instalaciones termales (sub se incollato et consumato), costeadas con su fortuna personal $\left({ }^{23}\right)$, ya que la inscripción, como en el caso anterior, no permite sospechar ni de lejos el patrocinio imperial. Las dedicaciones a Fortuna en Hispania están frecuentemente relacionadas con los establecimientos termales y además suelen estar dedicadas por militares $\left({ }^{24}\right)$, por lo que esta inscripción debe enmarcarse en este contexto.

En él, se incluye otra inscripción de Hispania dedicada a la Fortuna, erigida en honor de la Fortuna Balneari en Duratón (Segovia) ${ }^{25}$ ) por Valerius Tueco, soldado de la Legio II Adiutrix, y fue encontrada junto a una fuente en la que aparecen restos de arqueológicos de unas posibles termas $\left({ }^{26}\right)$.

En ambos casos, debemos hacer notar que la munificencia en favor de la población civil de Petavonium, que indirectamente también

(22) S. Carretero Vaquero y Ma.V. Romero Carnicero. Los campamentos... p. 46.

(23) E. Melchor GIL. "La Construcción...” pp. 152-153, tabla 2, desconoce esta inscripción, aunque si la cita en "Construcciones Cívicas y Evergetismo en la Hispania Romana”. RTF 6, 1993, p. 450, nota 9, otorgándoles la consideración de baños públicos.

${ }^{(24)}$ I. KAJANTO. "Fortuna". AVVILII, 17.1, Berlin 1981, p. 509.

(25) $C I L$ II, 2763 = P. LE Roux. L'Armée... n. ${ }^{\circ} 117=$ L. S AGREDo SAN EUSTAQUIO y A. JIMÉNEZ DE FURUNDARENA. "La Religion...” p. 314, n. ${ }^{\circ} 4$.

(26) I. KAJANTO. "Fortuna..." p. 509. 
alcanzaba a los soldados, no despertaba ninguna clase de suspicacias en la corte imperial. Sin embargo, un evergetismo directa de los prefectos del ala en favor de sus subordinados, costeado con su peculio personal, sería inmediatamente identificada con un deseo de atraerse a los soldados para sabe Dios que fines, lo que era una de las mejores maneras de ser castigado por orden del emperador con el destierro, e, incluso con la muerte, ya que, en un estado como el romano, que no era más que una dictadura militar encubierta, el evergetismo en favor de los soldados era patrimonio exclusivo del Emperador, que utilizaba este medio para asegurar la fidelidad de la base más importante de su poder: el ejército profesional. 


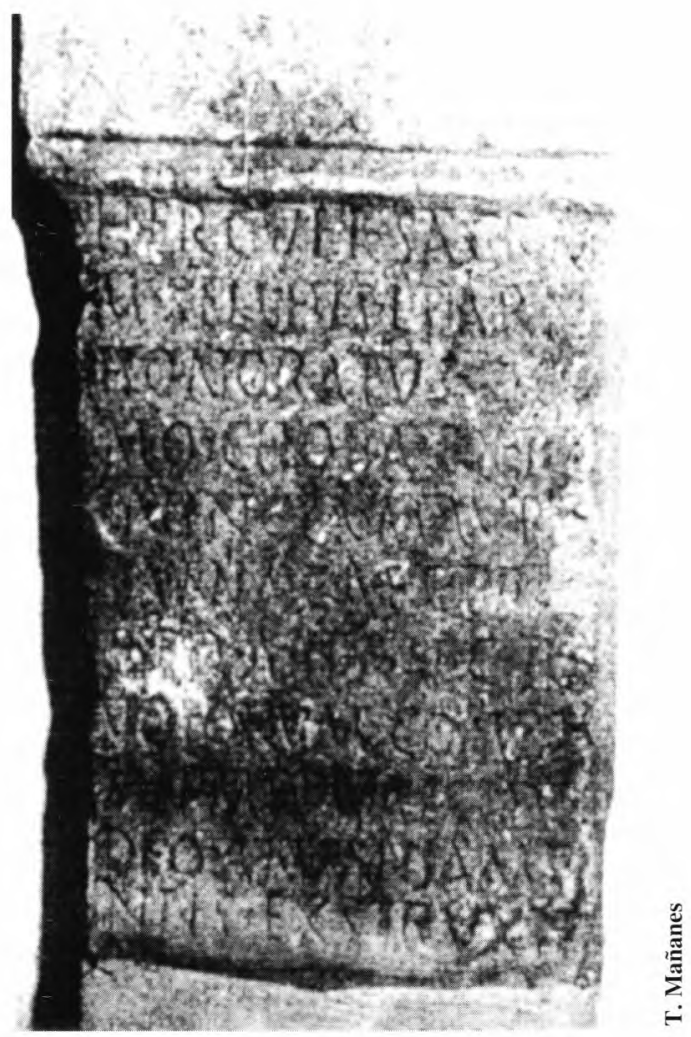

Foto 1 - Inscripción de M. Sellius Honoratus en honor de Hércules 


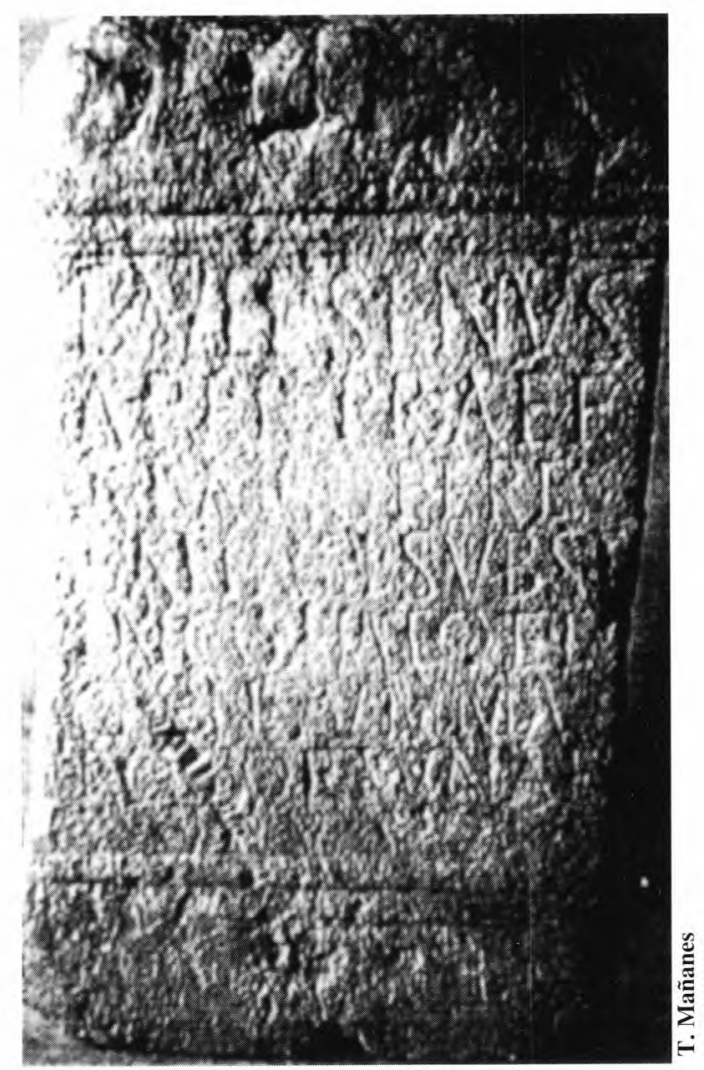

Fото 2 - Inscripción de L. Versenus Aper en honor de la Fortuna 